\title{
Response to Intervention: Perspectives of General and Special Education Professionals
}

ABSTRACT: Federal legislation allows local education agencies to use a student's response to scientific research-based interventions as a method of identifying specific learning disabilities. As a result, educational leadership is challenged to implement response to intervention (RTI). Despite increased literature addressing $\mathrm{RTI}$, no consensus on implementation has been reached. This national study was conducted to capture and report general education and special education professionals' perceptions and implementation practices of RTI. Study participants were randomly selected to include general and special education administrative, instructional, or support personnel on elementary and high school campuses. The wide variances, misunderstandings, and lack of training reported in this nationwide study could explain the mixed results of recent research on RTI. Implications for school leadership are deduced from the data and highlight the need for preservice and continuing professional development concerning all aspects of RTI.

Before the 2004 reauthorization of the Individuals with Disabilities Education Improvement Act (IDEA), students were identified with learning disabilities (LDs) by the determination of a significant discrepancy between their measured potential and displayed academic achievement. L. S. Fuchs and Fuchs (1998) suggested that the rapid growth in the LDs category was in part due to the use of different instruments and poor reliability in discrepancy scores, which created inconsistencies among districts in the identification of LDs. The reauthorization of IDEA permitted an alternative approach: response to intervention (RTI). RTI was created for determin-

Address correspondence to Susan C. Bineham, 9318 Chaddsford, San Antonio, TX 78250. E-mail: scbineham@utexas.edu. 
ing whether struggling learners should be referred for more in-depth assessment of specific LDs. The RTI process was to provide evidence of a student's response to scientific, research-based interventions as a means of determining whether a student had a specific LD. The National Joint Committee on Learning Disabilities (2005) suggested the following:

An RTI approach has been suggested as a way to reduce referrals to special education by providing well-designed instruction and intensified interventions in general education, thereby distinguishing between students who perform poorly in school due to factors such as inadequate prior instruction from students with LD who need more intensive and specialized instruction. (p. 2)

In principle, D. Fuchs and Fuchs (2008) noted that "RTI identifies which students have disabilities early in their education, decreases the number of students referred to special education programs, and reduces the over identification of minority students to special education, it is an ambitious and complex process" (p. 73).

\section{PURPOSE OF RTI}

The RTI procedure was conceptualized to move struggling students through a series of interventions that allow educators to identify areas of learning weakness. The National Joint Committee on Learning Disabilities (2005) offered the following description:

Although there is no universal RTI model, it is generally understood to include multiple tiers that provide a sequence of programs and services for students showing academic difficulties. Briefly, Tier 1 provides high-quality instruction and behavioral supports in general education, Tier 2 provides more specialized instruction for students whose performance and rate of progress lag behind classroom peers, and Tier 3 provides comprehensive evaluation by a multidisciplinary team to determine if the student has a disability and is eligible for special education and related services. (p. 14)

It was reported (Samuels, 2010) that some researchers assert that this tiered approach has reduced referrals to special education. Denton, Fletcher, Anthony, and Francis (2006) contended that "examining more closely fully articulated examples of multi-tiered approaches to instruction and their link to special education would prove valuable, especially in terms of the question whether such approaches reduce referral and identification rates for students with learning disabilities" (p. 464). 


\section{BACKGROUND}

Historically, RTI had a research base in the areas of medicine (Gresham, 2007a) and psychology (Kratochwill, Clements, \& Kalyomn, 2007). In the Handbook of Response to Intervention, Gresham (2007a) found that the majority of literature traced the basis of RTI in education to the 1982 National Research Council report by Heller, Holtzman, and Messick. The report discussed the quality of general education programs, special education programs, and assessment processes in the identification of a disability. It critiqued the IQ-achievement discrepancy model and proposed $\mathrm{RTI}$ as a method of $\mathrm{LD}$ identification. In this initial proposed model, there would be a verification of quality instruction, reliable and valid assessment measures, objective evidence that the student had not learned what was taught, and systematic efforts to determine the source of difficulty and take corrective measures using evidence-based interventions with increasing intensive instruction. In essence, similar to a medical model, RTI was to determine a child's response to a treatment, and the treatment was to be intensified or altered if the child showed no initial response to the intervention.

\section{CONCERNS ABOUT RTI}

\section{IMPLEMENTATION}

Despite increased professional literature addressing RTI, no consensus has been reached, but a variety of concerns have been reported-namely, poor treatment validity, lack of research-based interventions, confusion in the process of diagnosis of a disability (Burns, Jacob, \& Wagner, 2008; Gresham, 2007a; Reynolds \& Shaywitz, 2009), vagueness of a RTI definition (Kavale, 2005), lack of defined measures and criteria used in the implementation process (Witsken, Stoeckel, \& D'Amato, 2008), assessment considerations (Gresham, 2007b), lack of extensive professional development (Fletcher \& Vaughn, 2009), and an overall need for more research on the development and implementation of RTI frameworks in large-scale situations (D. Fuchs \& Deshler, 2007; Scruggs \& Mastropieri, 2006; Vaughn $\&$ Fuchs, 2006). Werts, Lambert, and Carpenter (2009) probed special education directors in North Carolina to determine their perceptions of the RTI role of school personnel, time needed for instructional sessions, and considerations needed for implementation. They concluded that there was little consensus across these areas. Similarly, Sansosti, Noltemeyer, and Goss (2010) conducted a nationwide survey of secondary school principals regarding RTI. The authors reported that the principals indicated knowl- 
edge of RTI, but there was a discrepancy between their indication of the importance of RTI and its implementation. The authors proposed that the discrepancy could be due to the lack of evidence-based interventions and systematic data collection in secondary schools as well as the difficulty in scheduling. To determine the extent that RTI was being utilized in the field of teacher education, Job, Gallagher, and Coleman (2010) surveyed the members of the Teacher Education Division of the Council for Exceptional Children. They concluded that teacher education preparation programs should incorporate a larger emphasis on the rationale, principles, and implementation procedures for RTI for preservice teachers to fully understand the various components of the RTI framework and appreciate how the framework fosters collaboration between general and special education.

\section{LACK OF GUIDELINES}

IDEA noted that a school "may use a process that determines if the child responds to scientific, research-based intervention as part of the evaluation procedures" of a LD ( $§ 1414 . b .6)$. However, there were no legislated guidelines for the implementation of RTI included in the act addressing the necessity of collaboration between general and special education. Therefore, such practice has been awkward at best. The literature related to RTI has no clearly defined processes, or standardized implementation models for RTI (Scruggs \& Mastropieri, 2006). This lack of standardization is troubling, as currently 43 of 50 states report having an RTI framework (National Center on Response to Intervention, 2010). In addition, there is a lack of research-based interventions (Burns et al., 2008; Gresham, 2007a; Reynolds \& Shaywitz, 2009). Clearly, RTI implementation can be improved by more research on the development and implementation of RTI frameworks in large-scale situations (D. Fuchs \& Deshler, 2007; Scruggs \& Mastropieri, 2006; Vaughn \& Fuchs, 2006).

\section{RATIONALE FOR STUDY}

In an effort to determine the held perceptions of RTI by educational personnel, a nationwide survey was conducted soliciting the opinions of randomly selected administrative, instructional, and support personnel (general and special education) at the high school and elementary levels from schools in all 50 states and the District of Columbia. The study does not include middle school or junior high because of inconsistencies among districts in defining which grades are included. The team decided that using elementary schools (which sometimes include Grade 8) and high 
schools (which typically begin in Grade 9) would capture the public school landscape.

The survey sought to answer the following questions:

What is the understanding of general and special education professionals regarding RTI?

How is RTI implemented in various settings?

What experiences contributed to the professionals' knowledge of RTI?

\section{CONCEPTUAL FRAMEWORK: ADVANTAGES OF RTI}

RTI emphasizes progress monitoring and recommends the use of not only curriculum but also classroom-based assessment, student portfolios, criterion-referenced achievement measures, and teacher observations (National Joint Committee on Learning Disabilities, 2005). As a result, information pertaining to the types of instructional strategies and interventions that were attempted and details concerning "what did not work or what has not been tried" (p. 6) should be available if the student is identified as having a LD. Information from early interventions should assist the individual education program (IEP) team in developing the student's IEP.

\section{EARLY IDENTIFICATION OF LDS}

A key element of RTI is the early identification of struggling learners and the provision of early intervention when students first experience academic difficulties, with a goal to improve the achievement of all students, including those who may have a LD. In addition to prevention of learning difficulties and remedial services needed, RTI provides useful data in the process of early identification of LDs (National Joint Committee on Learning Disabilities, 2005).

Gettinger and Stoiber (2008) applied the RTI framework to determine the early literacy and language skills of low-income students in Head Start classrooms. The authors implemented a RTI approach in 15 classrooms with 10 matched control classrooms. The classrooms consisted of $90 \%$ to $95 \%$ African American students, $6 \%$ to $10 \%$ Hispanic, and less than $2 \%$ White or other. The results indicated a significant improvement in the RTI treatment group in all areas of language skills. The authors concluded that the benefit of using RTI as an intervention for young children "is consistent with the increasing emphasis on early intervention and scientifically based early literacy instruction" (p. 209). 


\section{DECREASE IN REFERRALS TO SPECIAL EDUCATION}

Recent research has noted decreases in the number of students identified as having LDs, as a result of RTI (Marston, Muyskens, Lau, \& Canter, 2003; Samuels, 2010; Torgesen, 2009). Furthermore, Dexter, Hughes, and Farmer (2008) concluded that RTI facilitated more appropriate referrals to special education. However, Samuels (2010) posited that the decrease could be due to shifting students from one category to another.

\section{REDUCTION IN DISPROPORTIONALITY OF MINORITIES IN SPECIAL EDUCATION}

The U.S. Census Bureau (2010) reported major population increases in ethnic and racial minority children in the United States. Artiles (2003) noted that schools are challenged by increases in the diversity of the population. Furthermore, the census indicated that a large number of these children speak a language other than English and are considered to be less secure financially and physically: all factors that place them at risk for special education referral. A leading concern in the field of special education is overrepresentation of minorities and students with low socioeconomic status who experienced failure in general education and were placed in special education (Dudley-Marling, 2004). Although RTI has been promoted as an alternative method for identifying LDs, it holds some promise for addressing ethnic disproportionality in special education. Nevertheless, there is a lack of literature concerning research-based interventions appropriate for many culturally and linguistically diverse students, which raises questions about the validity of interventions with this growing population.

\section{African Americans}

Marston and colleagues (2003) noted a population increase in the number of African American students from 1997-1998 to 2000-2001; however, in 2000-2001, fewer African American students were referred to the (RTI) support team, fewer were evaluated for special education, and fewer were placed in special education. Although these results are encouraging, the study did not have a control group or use random selection, which limits generalization of these findings.

\section{English-Language Learners}

Harris-Murri, King, and Rostenberg (2006) stressed the importance of a culturally responsive approach to the implementation of RTI for culturally 
and linguistically diverse students, adding that consideration and understanding of language and culture in implementing interventions is necessary for appropriate eligibility determination and prevention of disproportionate representation in special education. Similarly, Rinaldi and Samson (2008) expressed a need for RTI to consider culture and language: "The most salient difficulty in assessing ELL [English-language learner] students who exhibit academic difficulties is identifying whether the problem is one of English proficiency or of a learning disability" (p. 13). Linan-Thompson, Cirino, and Vaughn (2007) implemented RTI with 41 first graders (compared to 40 in the control group) who were ELL. The results were varied, with $88 \%$ of the control group not passing the Grade 1 or 2 criteria, as opposed to $75 \%$ to $80 \%$ of the treatment group. The data provided some encouragement but posed more questions than answers. Kashi (2008) provided the following analysis after studying a rural Alaskan district with three major ethnic minorities that achieved adequate yearly progress goals 2 years in a row after implementing a RTI process:

Another benefit is RTI's sensitivity to human diversity and hope for those who struggle with learning because of their cultural, linguistic, or ethnic differences. For those individuals with different learning styles, different backgrounds, different languages, different lifestyles, and so on. (p. 42)

Utilizing the RTI process when evaluating ELLs may prove to be difficult. Ortiz, Wilkinson, Robertson-Courtney, and Kushner (2006) hypothesized that the school-related problems of ELLs "may be the result of teachers' lack of preparation and experience in working with these students" (p. 56). In addition, Ortiz and colleagues posited, "Educators who had key roles - directly or indirectly - in eligibility determinations, including teachers, pre-referral and referral committees, and multidisciplinary teams, had difficulty distinguishing between linguistic and cultural differences and specific disabilities" (p. 54).

\section{THEORETICAL FRAMEWORK}

Gersten, Vaughn, Deshler, and Schiller (1997) described innovation as affecting everyone on a very personal and psychological level. The results of this survey suggested how the adoption of RTI as an innovation has affected different individuals within the $\mathrm{K}-12$ education system. RTI may be viewed as a new innovation. Rogers's (2003) presented a model of diffusion and the adoption of innovation in organizations. Rogers's model would define the decision to implement RTI as an authority innovation decision - that is, choices to adopt or reject an innovation are made by a 
relatively few individuals in a system who possess power, status, or technical expertise (p. 372).

According to Rogers (2003), the adoption of an innovation follows five stages. The first two are part of the decision-making process. The first stage is initiation. In this stage, information is gathered; conceptualizing and planning for the innovation leads to the decision to adopt (p. 391). The second stage is matching. At this stage, the problem is analyzed to determine how it fits the innovation (p. 394). The next three steps-redefining/ restructuring, clarifying, and routinizing - concern implementation of innovation within organizations. Redefining/restructuring occurs when the innovation is reinvented to accommodate the organization's needs and when the organization's structure is modified to fit the innovation (p. 394). Clarifying occurs over time when an innovation is put into more widespread use in an organization. The meaning of the new idea gradually becomes clearer to the organization's members. A rapid implementation of an innovation at the clarifying stage often leads to disastrous results (p. 399). Routinizing occurs when the innovation has become incorporated into the regular activities of the organization and the innovation loses its separate identity. At this point, the innovation process in an organization is complete (p. 399).

The innovation decision-making process is much less complex for individuals than for organizational adoption. Yet, individuals within organizations must also adopt innovations to guarantee success. Rogers (2003) suggested that successful adoption of innovation on the individual level must include the following five intrinsic elements: relative advantage, in which the innovation is perceived as being better than the current status; compatibility, with existing values and experience; complexity, or how easy the innovation is to understand; trialability, the ability to be tried on an experimental basis; and observability, the ability to see the positive results.

\section{METHOD}

\section{CONSTRUCTION OF RTI DEFINITION}

With the existence of ambiguity in definitions of RTI, there was a need to develop a definition of it. We conducted a review of the literature and compiled RTI definitions from special and general education refereed journals, federally funded RTI research centers, national nonprofit RTI initiatives, individual state RTI definitions, and the language associated with RTI in IDEA ( $\S 614 . b .6 B)$. Following this review, we completed a content analysis 
of the identified definitions. Glasne (2006) suggested a grounded theory approach as a method for coding, comparing, and identifying emergent concepts in social science qualitative research. Grounded theory procedures were used to identify essential elements of an RTI definition, and research team consensus produced the following definition:

RTI is a multitiered framework utilized by schools for the purpose of early identification of learning difficulties or diagnosis of a specific LD. This framework consists of universal screening, high-quality instruction with increasingly intense research-based interventions, continuous monitoring of student performance and occurs prior to a determination of need for special education support and services.

\section{RESEARCH DESIGN}

A 40-item survey was developed to assess professionals' held perceptions of RTI and implementation practices. It was designed to collect data from general and special education: administrators, direct instruction teachers, and special support personnel. The survey included questions related to specific practices in three categories: the roles of teachers and other personnel in implementing RTI, the duration of RTI interventions, and the decisions made relative to the implementation in the classroom.

\section{Survey}

Part 1. The first part of the survey contained 25 items pertaining to participants' perspectives on plans for using RTI in their school districts, the rationale for change, and their perceptions of the benefits and challenges to implementation. Thirteen questions were based on a Likert-type scale (e.g., strongly agree to strongly disagree, significant increase to significant decrease). The team decided on a 4-point scale to eliminate neutral responses. Ten questions used a forced-choice format, and two asked participants to rank order their responses. One open-ended question was included to allow additional comments.

Part 2. Fifteen questions pertained to participant and district demographics. Open-ended questions captured the participants' explanations of how RTI was implemented in their districts.

\section{Pilot of Survey}

Professionals who were associated with a university department of special education reviewed the preliminary draft of the survey. The professionals' roles and backgrounds were as follows: special education 
teacher, principal, special education director, professor of communication disorders, two professors of special education, and an adjunct professor of special education. Recommendations to add, delete, or revise the survey were incorporated and a revised draft distributed to the same professionals for final additional feedback.

\section{PARTICIPANTS}

\section{Selection Criteria}

Participants. General and special educators who were in administrative, instructional, or support positions at the district and campus levels were randomly selected from all 50 states and the District of Columbia.

Districts. The website for the National Center for Education Statistics (2010) was used to find the number of districts within each state and Washington, DC. This website assigns a number to each district within the state. To randomly select school districts within each state (and the District of Columbia), random integers were generated via random.org (http://www. random.org/integers/) and matched to the numbers assigned by the center's website. In like manner, state education agency websites provided lists for random assignment of school district campuses.

\section{Random Selection}

School districts. The team randomly select $5 \%$ of the school districts within each state and the District of Columbia. If the state had more than 500 school districts, 20 were randomly selected instead of $5 \%$.

Campuses. Within each district, an elementary school and a high school were randomly selected. If a selected district contained only one elementary school or high school, that school was chosen. If only one elementary school existed with no high school, the elementary school was chosen, with the lack of a high school noted. If only one high school existed with no elementary school, the high school was selected. If the district contained more than one elementary school or high school, random-generated numbers for the district identified schools for participation.

Participants. The following information was gathered from district websites: size of district, size of school, school location (address, phone number), number of students, and grade levels for each school or district. If e-mail addresses were not available, the school was eliminated, and we utilized the random selection process to select another school. Once the schools within a school district were selected, we used the school's website to find a listing of staff e-mail. The administration, 
general education, and special education staff were numbered in the order that they appeared, according to departments. The first name on the list was numbered 1 , the second name 2 , and so on. The participants were then randomly selected with the random-generated integers website. In some cases, we contacted the schools by telephone to verify e-mail addresses.

\section{SURVEY DISTRIBUTION}

To collect responses, we used SurveyMonkey (http://www.surveymonkey.com). Undeliverable e-mail received one e-mail follow-up, complying with districts' e-mail security measures.

\section{RESULTS}

\section{PARTICIPANT DEMOGRAPHICS}

Of the surveys distributed, 627 responses provided a return rate of $22 \%$. This rate is similar to a national meta-analysis that reported a $26 \%$ median response rate to Internet surveys (Hamilton, 2009). The strict random-sampling processes provide additional confidence in the response rate. Table 1 provides an overview of the participant demographics. The team chose not to compare district general and special education personnel since many indicated that they taught in both areas. Additionally, the analysis reported in this article aggregates general and special education responses.

\section{PARTICIPANTS' RESPONSES}

Ninety percent $(n=554)$ of the participants were aware of RTI. However, and surprising, almost 1 in $10(n=61)$ professionals had not heard of RTI. Those who had never heard of RTI were exited from the survey.

Given the range of participant characteristics presented in Table 1, it is interesting to note the descriptions of responsibilities provided by respondents-for example,

"Provide specially designed instruction, hold special education decision committees, write IEPs, provide documentation pertaining to special education decision committees and IEPs."

"Develop protocol for assessments, deliver instruction, provide professional development."

"Teaching, paperwork." 
Table 1. Participant Demographics

\begin{tabular}{|c|c|c|}
\hline Category & $n$ & $\%$ \\
\hline \multicolumn{3}{|l|}{ Gender } \\
\hline Male & 223 & 36 \\
\hline Female & 396 & 64 \\
\hline \multicolumn{3}{|l|}{ Ethnicity } \\
\hline White & 561 & 91 \\
\hline Hispanic & 14 & 2 \\
\hline African American & 26 & 4 \\
\hline American Indian/Alaska Native & 12 & 2 \\
\hline \multicolumn{3}{|l|}{ Level of education } \\
\hline Bachelor & 118 & 19 \\
\hline Master & 451 & 73 \\
\hline Doctorate & 47 & 8 \\
\hline \multicolumn{3}{|l|}{ Type of position } \\
\hline Administration (principal, assistant principal, etc.) & 301 & 49 \\
\hline Instruction (teacher) & 285 & 46 \\
\hline Support (therapist, diagnostician, assessment) & 55 & 9 \\
\hline \multicolumn{3}{|l|}{ Type of service provider } \\
\hline General education & 176 & 28 \\
\hline Special education & 226 & 36 \\
\hline Both & 296 & 47 \\
\hline \multicolumn{3}{|l|}{ Participant work site } \\
\hline Secondary & 252 & 41 \\
\hline Elementary & 202 & 33 \\
\hline Both & 161 & 26 \\
\hline Campus-level assignment & 410 & 68 \\
\hline Central office & 120 & 20 \\
\hline Both & 36 & 6 \\
\hline Other & 36 & 6 \\
\hline \multicolumn{3}{|l|}{ Participants' position funding } \\
\hline Local/district funds & 439 & 72 \\
\hline Federal—special education funds & 161 & 26 \\
\hline Federal— title or general education funds & 107 & 18 \\
\hline Did not know & 61 & 10 \\
\hline Other & 23 & 4 \\
\hline
\end{tabular}

Note. Numbers and percentages are based on the number of answers and do not include those who skipped the question. Furthermore, participants selected multiple responses for some answers. As such, percentages may not add up to 100. Examples of participant-reported certifications: K-12 learning behavior disorders, K-5 elementary, master-level special education certification, currently working on master in educational leadership, teacher of the handicapped elementary education, K-8 leaning consultant, supervisor, principal/director, school counselor.

\section{"Administrator of a PreK-grade 4 school."}

"Run the district."

Responses indicated that in many places, the school or district was at the beginning stages of adoption and implementation. Several respondents noted that the school was in the first, second, or third year of implementa- 
tion. More than $13 \%$ of the districts $(n=55)$ were in the first year or had not begun implementation of RTI; $12 \%(n=48)$ had not implemented RTI; $2 \%(n=7)$ indicated that they were in their first year. Some respondents expressed their experience with the RTI concept as follows:

"We are monitoring policy at the state level prior to a full commitment." "Ignored; not dealt with; a meaningless buzzword."

"They are three letters that the county office folks use, and we've seen the book in someone's hand once or twice."

\section{Description of RTI}

Respondents articulated many descriptions of RTI. It was described as a process, program, instructional strategy, model, team, remediation, special education, and additional work for teachers. According to the survey, RTI can be conceptualized as a noun, verb, or adjective, as illustrated in the following comments.

RTI is a process.

"It is a very structured process involving the entire team. . . . We identify student's academic, social or behavior struggles and plan interventions." "It is the process that we use to evaluate and intervene with students who are underachieving."

"We have an RTI process for struggling learners."

RTI is a program.

"We meet monthly to review progress of students we have put into RTI." "We have had a full time RtII [response to instruction and intervention]." "Program in my building for 2 years. It is very effective."

"RTI is a reading intervention program intended to identify and help struggling readers."

RTI is an instructional strategy.

"[RTI is an] instructional strategy to facilitate learning for students who are struggling in school."

"We use research based interventions, common assessments and progress monitoring."

"[We] discuss educational strategies that need to be implemented."

RTI is model.

"We have a framework based on the RTI model. Interventions are being carried out in $\mathrm{K}-6 . "$ 
"We have the 3 tier model and use the I Station program."

"We have a tiered instruction model . . . with formal and informal assessment to progress monitor."

RTI is a team.

"The Intervention and Referral Services Committee meets and forms RTI." "[RTI is an] assistance team ... for low statewide test performance."

"A team of school professionals meet to identify at-risk students . . . make recommendations."

RTI is remediation.

"We have tutoring available, help from teachers, differentiated instruction, and a RTI study hall to give students some additional instruction."

"We have remediation labs in reading and math for students behind grade level."

"We have a specific intervention time set daily."

RTI is eligibility for special education.

"Our school is applying RTI in placing a middle school student in special education."

"[RTI is] special education evaluation."

"[Students] must go through the RTI process and try different interventions before they can be referred to 504 or Special Ed."

RTI is special education.

"[RTI is] inclusion classes and individualized instruction for special needs students."

"Used in our Special Ed department."

"[RTI is] very data driven; required on our IEPs."

RTI is additional work for the teacher.

"We struggle to work RTI into the high school since we see so many students each day."

"General education teachers have to do almost a year's worth of intervention before being considered for special education services."

RTI Implementation

Twelve percent of the respondents $(n=48)$ mentioned tiers; $65 \%(n=$ $31)$ mentioned three tiers. Sixteen percent $(n=66)$ reported elementary school implementation. Fourteen percent $(n=58)$ noted implementation 
in reading, $9 \%(n=38)$ in math, and $4 \%(n=17)$ in behavior. Three percent $(n=14)$ reported using packaged interventions.

\section{Use of RTI}

Although federal law (IDEA, 2004) states that RTI is an allowed alternative for identification of specific LDs, $47 \%(n=208)$ of respondents believed that federal law requires RTI. One of the more interesting findings is that although the law allows RTI as an alternate method for identification of specific LDs, Figure 1 indicates that RTI is being applied or is perceived to be applicable to the identification of all special education disability categories.

In addition, an interesting dichotomy is shown in Figure 2. While approximately $63 \%(n=288)$ agreed that RTI was appropriate for Englishlanguage learners, only $35 \%(n=159)$ rated RTI as a culturally sensitive procedure.

\section{Confusion About RTI Implementation}

When asked about professional development, 1 in 3 respondents stated that he or she had not received professional development training in RTI. One-third also indicated confusion about who is responsible for RTI; 72\% $(n=324)$ cited the general education teacher. However, the second-most frequent response $(58 \%, n=258)$ cited the special education teacher or the principal/assistant principal. The lowest number $(48 \%, n=213)$ identified the intervention specialist as being responsible.

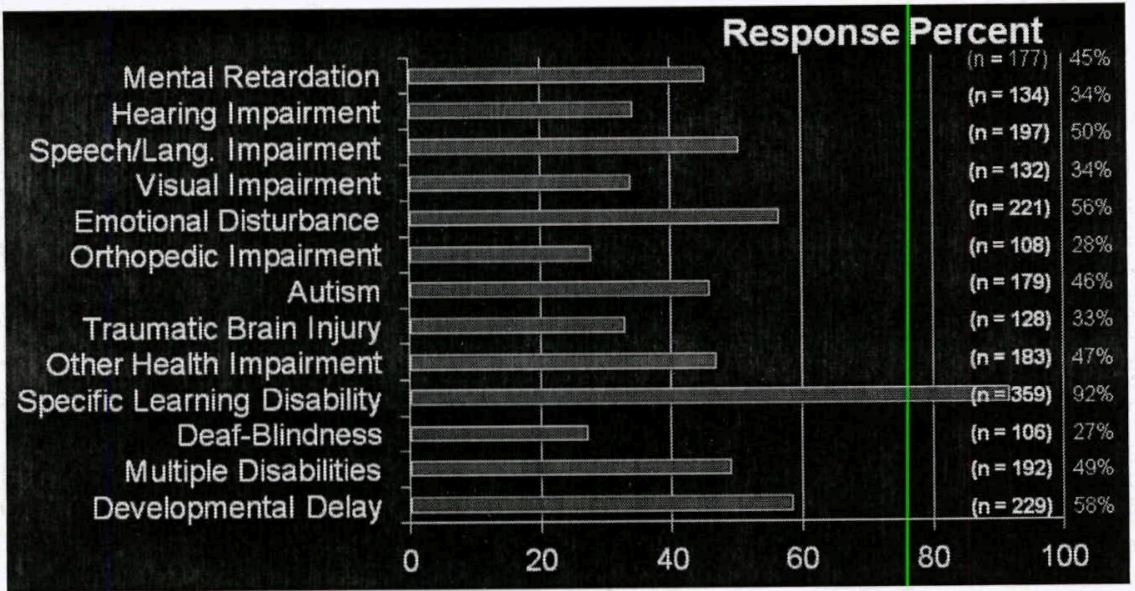

Figure 1. RTI Applied to All Disabilities. 


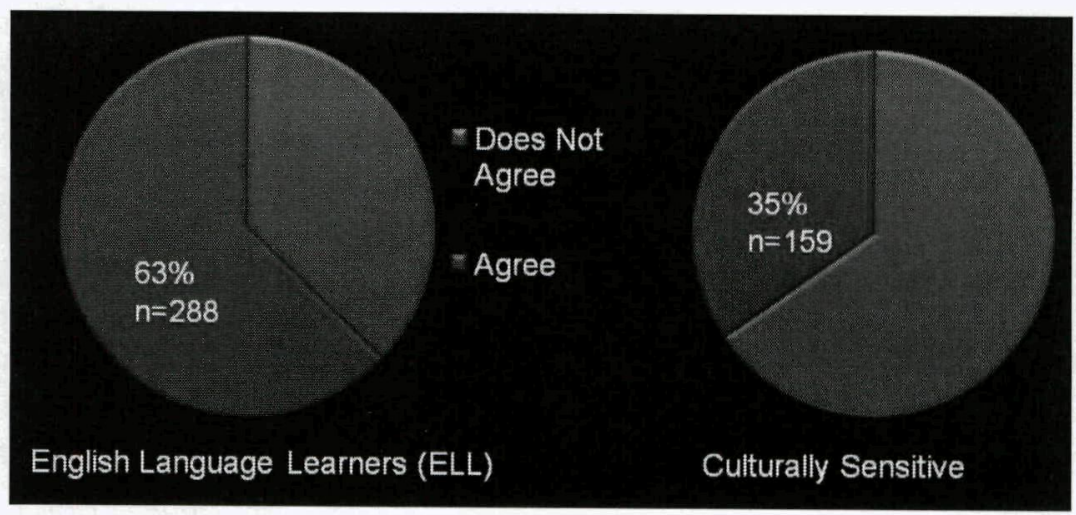

Figure 2. RTI for ELL and Culturally Sensitive?

Further evidence of confusion regarding responsibility is seen in respondents' identification of parents, older students, reading consultants, psychologists, county administrators, program coordinators, and behavior specialists as being responsible for RTI. Although RTI is conceptualized as a general education intervention (i.e., before special education), $53 \%$ ( $n=$ 241) of the respondents indicated that special education teachers implement RTI, suggesting that the respondents perceive the child as already receiving special education.

It is interesting to note the full range of persons identified as implementing RTI: psychologist, paraprofessional, instructional aide, tutor, everyone, committee, specialist (music, art, physical education), teaching assistant, language arts consultant, behavior specialist, speech/language therapist, reading/math specialist, parent, extended school services, and the entire team. A total of $63 \%(n=284)$ of the respondents perceived that the general education teacher was responsible for selecting interventions, while the special education teachers were perceived as selecting the intervention $51 \%$ ( $n=231$ ) of the time. It was surprising that respondents perceived that the principal or assistant principal $(46 \%, n=207)$ selected interventions for RTI. The expertise of diagnosticians in selecting interventions was utilized less than the administrator, according to $23 \%(n=105)$ of the respondents.

\section{DISCUSSION AND CONCLUSIONS}

Oliver (1996) reported that "change seems a much more likely characteristic of education than stability" (p. 2). While change may be the most predictable trait of public education, it is also one of the aspects of 
administration that presents the greatest challenges to leaders. Huberman and Miles (1984) suggested, "If the innovation literature teaches us one thing, it is that in practice change is an uneven, uncertain affair that seldom transcends trivial levels" (p. 25).

\section{NEED FOR PROFESSIONAL DEVELOPMENT}

Based on the wide range of different responses to the survey, all levels of educational personnel (administrative, instructional, and support) need training related to RTI. Fletcher and Vaughn (2009) noted that "providing effective Tier I instruction to all students requires ongoing professional development, screening, progress monitoring students' and that "maintaining these practices demands extensive professional development" (p. 31). For example, respondents indicated that principals were critically and centrally involved in the RTI process, making decisions on organizational implementation, allocation of resources for professional development, and so forth. However, respondents also believed that administrators are in need of additional information related to RTI. These responses raise a critical question: Do administrator preparation programs include RTI training, and, if not, where might RTI be integrated into their preparation? Similar concerns apply to the preparation of instructional and special support professionals. These questions and concerns highlight the need for review of certification requirements to determine the necessity of including RTI content and training.

\section{GAPS}

The results of this study appear to indicate a disconnect between theory and actual practice. Perhaps the reason for many RTI models is a lack of clear federal guidelines. Fewer than $47 \%(n=218)$ of those surveyed thought that RTI was mandated by federal law; therefore, there was no choice in implementing it. However, those involved in implementation of new innovations must feel a sense of ownership in development for the innovation to be successful (Gersten et al., 1997). This affirms Rogers's (2003) authority innovation decision category, where the decision to implement an innovation is made by a few individuals who possess power. At the time that this study was conducted, most school districts in the nation were in their first 3 years of RTI implementation, what Rogers called early adoption. Organizations are still at the first stage of adoption, initiation, where information is being gathered. Almost $10 \%(n=61)$ of those surveyed had not heard of RTI, indicating that such information is still not universal. 
Some organizations are at Rogers's (2003) matching stage, where the organization appears to be planning and designing the innovation to match the its problems. Gersten and colleagues (1997) stated that improvement occurs when individuals infuse new knowledge into their current practice. Other organizations appear to be in the redefining/restructuring stage of adoption as they attempt to accommodate their need to respond and implement the innovation. Some also appear to be at the clarifying stage. For example, some states were developing policy, and some districts were creating manuals; yet, at the same time, some individuals at the campus level were trying to determine how to fit RTI into the secondary schedule, whereas others felt that RTI was being ignored altogether. Clearly, implementation of RTI has not been consistent and the routinizing stage of adoption not yet met. Survey results suggest that universal adoption of RTI as an innovation has not yet occurred. The inconsistent and variable responses to this survey seem to support the conclusion that RTI has not yet successfully moved through the stages of adoption.

\section{IMPLICATIONS}

The need for preservice and continuing professional development is clear, as respondents were all practicing professionals. Whitaker (1993) noted that "organizational change occurs only as a consequence of changes in the individual" and that "it is the individuals' view of themselves that changes, not the organization" (p. 101). Viable areas for continuing education include training in the following: curriculum-based interventions, the changing roles of diagnosticians and other special support professionals, curriculum-based assessment training, and assessments that are organizational or systemic.

Findings of this study suggest future projections for the adoption of RTI. Rogers (2003) has suggested that successful adoption of innovation must include five intrinsic elements: relative advantage (perceived as being better than current status), compatibility (perceived as being consistent with existing values and experience), complexity (perceived as being easy to understand), trialability (feasible on an experimental basis), and observability (apparent positive results). With regard to relative advantage, the innovation of RTI within the educational system was based on a law rather than empirical data, which might have demonstrated that RTI is a better model than the past/current discrepancy model in determining specific LDs. Everard and Morris (1996) emphasized the importance of leadership that engages in "a process of interaction, dialogue, feedback, modifying objectives, recycling plans, coping with mixed feelings and 
values, pragmatism micropolitics, frustration, patience and muddle" ( $\mathrm{p}$. 233). Therefore, to support the adoption of RTI, educational leaders must emphasize the relative advantage of RTI rather than the law. RTI appears to have obtained trialabililty in some districts, which reported that they phased in RTI by beginning with elementary schools and gradually incorporating secondary schools. It is important that educational administrators share their commitment to and plans for trialability with their educators and stakeholders. As RTI becomes widespread, there is the potential of observability. As the RTI results become observable, educational leadership can use the data to compare RTI with the previous practices, and this comparison could become part of a professional learning community. Educators will accept and implement effective ways of teaching once they know what they are (Gersten et al., 1997). However, at this point, more research is needed explaining the relative advantage of RTI use with various populations-for example, English-language learners and ethnic and racially distinct groups.

Furthermore, while implementation of RTI may be compatible with existing values, the process drastically alters the way that general education teachers address the needs of struggling learners, and it may be perceived as being less compatible to previously adopted instructional approaches or intervention models. Therefore, when examined from Rogers's (2003) perspective of the adoption of innovation, these survey results suggest that the RTI model is in a stage of early adoption and, for some, RTI is viewed as a mandatory adoption generated by external insistence suggesting that implementation will be difficult. If the legal and professional commitments to RTI were to move it into later stages of organizational adoption, this study would suggest a need for significant inclusion and expansion of RTI information in professional training. Brown (2006) suggested that because change involves an individual's shift in paradigms, leaders need to learn about theories for transformational adult learning. The author posited three theories for increasing administrators' awareness of the changes process: adult learning theory, transformative learning theory, and critical social theory (p. 2-3).

In light of the lack of clear research evidence indicating that RTI offers advantages that are distinctly different from past practice and given the lack of involvement and clear linkages of general and special education, there is limited evidence at this early stage regarding the efficacy of RTI. Major research efforts are needed to define RTI and examine the process, procedure, and product of RTI as it is adopted. The promise of improved services to students with disabilities and their parents would make these critical efforts worthwhile. 


\section{REFERENCES}

Artiles, A. J. (2003). Special education's changing identity: Paradoxes and dilemmas in views of culture and space. Harvard Educational Review, 73(2), 164-202.

Brown, K. M. (2006). A transformative andragogy for principal preparation programs. University Council for Education Administration Review, 45, 1-5.

Burns, M., Jacob, S., \& Wagner, A. (2008). Ethical and legal issues associated with using response-to-intervention to assess learning disabilities. Journal of School Psychology, 46(3), 263-279.

Denton, C., Fletcher, J., Anthony, J., \& Francis, D. (2006). An evaluation of intensive intervention for students with persistent reading difficulties. Journal of Learning Disabilities, 39(5), 447-466.

Dexter, D. D., Hughes, C. A., \& Farmer, T. W. (2008). Response to intervention: A review of field studies and implications for rural special education. Rural Special Education Quarterly, 27(4), 3-9.

Dudley-Marling, C. (2004). The social construction of learning disabilities. Journal of Learning Disabilities, 37(6), 482-489.

Everard, K. B., \& Morris, G. (1996). Effective school management. London: Chapman.

Fletcher, J. M., \& Vaughn S. (2009). Response to intervention: Preventing and remediation academic difficulties. Child Development Perspectives, 3(1), 30-37.

Fuchs, D., \& Deshler, D. (2007). What we need to know about responsiveness to intervention (and shouldn't be afraid to ask). Learning Disabilities Research \& Practice, 22(2), 129-136.

Fuchs, D., \& Fuchs, L. (2008). Professional opinion: Implementing RTI. District Administration, 9, 73-76.

Fuchs, L. S., \& Fuchs, D. (1998). Treatment validity: A unifying concept for reconceptualizing the identification of learning disabilities. Learning Disabilities Research and Practice, 13(4), 204-219.

Gersten, R., Vaughn, S., Deshler, D., \& Schiller, E. (1997). What we know about using research findings: Implications for improving special education practice. Journal of Learning Disabilities, 30(5), 466-476.

Gettinger, M., \& Stoiber, K. (2008). Applying a response-to-intervention model for early literacy development in low-income children. Topics in Early Childhood Special Education, 27(4), 198-213.

Glasne, C. (2006). Becoming qualitative researchers: An introduction (3rd ed.). Boston: Pearson.

Gresham, F. (2007a). Evolution of the response-to-intervention concept: Empirical foundations and recent developments. In S. R. Jimerson, M. K. Burns, \& A. M. VanDerHeyden (Eds.), Handbook of Response to Intervention (pp. 10-24). New York: Springer.

Gresham, F. (2007b). Response to intervention and emotional and behavioral disorders: Best practices in assessment for intervention. Assessment for Effective Intervention, 32(4), 214-222.

Hamilton, M. B. (2009). On line survey response rates and times. Bethesda, MD: Itpath. 
Harris-Murri, N., King, K., \& Rostenberg, D. (2006). Reducing disproportionate minority representation in special education programs for students with emotional disturbances: Toward a culturally responsive response to intervention model. Education and Treatment of Children, 29(4), 779-799.

Heller, K., Holtzman, W., \& Messick, S. (1982). Placing children in special education: A strategy for equity. Washington, DC: National Academy Press.

Huberman, A. M., \& Miles, M. B. (1984). Innovation up close: How school improvement works. New York: Premium Press.

Individuals with Disabilities Education Improvement Act, Pub. L. No. 108-446, 118 Stat. 2647 (2004).

Job, J., Gallagher, J., \& Coleman, M. R. (2010, winter). Conversations on RTI and teacher preparation. TEDLines, pp. 3-6. Retrieved from http://ted.arnimadev. com/uploads/doc/TEDLinesWinter2010.pdf

Kashi, T. L. (2008). Response to intervention as a suggested generalized approach to improving minority AYP scores. Rural Special Education Quarterly, 27(4), $37-44$.

Kavale, K. (2005). Identifying specific learning disability: Is responsiveness to intervention the answer? Journal of Learning Disabilities, 38, 553-562.

Kratochwill, T., Clements, M., \& Kalyomn, K. (2007). Response to intervention: Conceptual and methodological issues in implementation. Handbook of response to intervention. New York: Springer.

Linan-Thompson, S., Cirino, P. T., \& Vaughn, S. (2007). Determining English language learners' response to intervention: Questions and some answers. Learning Disability Quarterly, 30(3), 185-195.

Marston, D., Muyskens, P., Lau, M., \& Canter, A. (2003). Problem-solving model for decision making with high-incidence disabilities: The Minneapolis experience. Learning Disabilities: Research \& Practice, 18(3), 187-200.

National Center for Education Statistics. (2010). Search for public school districts. Retrieved from http://nces.ed.gov/ccd/districtsearch/

National Center on Response to Intervention. (2010). RTI state database. Retrieved from http://state.rti4success.org

National Joint Committee on Learning Disabilities. (2005). Responsiveness to intervention and learning disabilities. Retrieved from http://www.ldonline.org/ about/partners/njcld\#reports

Oliver, P. (1996). The concept of change management. In P. Oliver (Ed.), The management of educational change: A case-study approach (pp. 1-9). Brookfield, VT: Arena.

Ortiz, A. A., Wilkinson, C. Y., Robertson-Courtney, P., \& Kushner, M. I. (2006). Considerations in implementing intervention assistance teams to support English language learners. Remedial and Special Education, 27(1), 53-63.

Reynolds, C., \& Shaywitz, S. (2009). Response to intervention: Ready or not? Or, from wait-to-fail to watch-them-fail. School Psychology Quarterly, 24(2), $130-145$.

Rinaldi, C., \& Samson, J. (2008). English language learners and response to intervention: Referral considerations. Teaching Exceptional Children, 40(5), 6-14. 
Rogers, E. M. (2003). Diffusion of Innovations (5th ed.). New York: Free Press. Samuels, C. A. (2010). Boom in learning-disabled enrollments ends. Education Week, 30(3), 14-15.

Sansosti, F. J., Noltemeyer, A., \& Goss, S. (2010). Principals' perceptions of the importance and availability of response to intervention practices within high school settings. School Psychology Review, 39(2), 286-295.

Scruggs, T., \& Mastropieri, M. (2006). Response to "Competing views: A dialogue on response to intervention." Assessment for Effective Intervention, 32(1), $62-64$.

Torgesen, J. K. (2009). The response to intervention instructional model: Some outcomes from a large-scale implementation in Reading First schools. Child Development Perspectives, 3(1), 38-40.

U.S. Census Bureau. (2010). Table 5: Cumulative estimates of the components of resident population change by race and Hispanic origin for the United States: April 1, 2000 to July 1, 2009. Retrieved from http://www.census.gov. (NC-EST2009-05)

Vaughn, S., \& Fuchs, L. (2006). A response to "Competing views: A dialogue on response to intervention": Why response to intervention is necessary but not sufficient for identifying students with learning disabilities. Assessment for Effective Intervention, 32(1), 58-61.

Werts, M., Lambert, M., \& Carpenter, E. (2009). What special education directors say about RTI. Learning Disability Quarterly, 32(4), 245-254.

Whitaker, P. (1993). Managing change in schools. Buckingham: Open University Press.

Witsken, D., Stoeckel, A., \& D'Amato, R. C. (2008). Leading educational change using a neuropsychological response-to-intervention approach: Linking our past, present, and future. Psychology in the Schools, 45(9), 781-798.

Susan C. Bineham is a doctoral candidate in the special education administration doctorate program at the University of Texas at Austin. She has 15 years of experience as a special education teacher, department coordinator, and campus coordinator in one of the largest urban school districts in the state of Texas. She guest lectures for local teacher certification programs speaking about the Individuals with Disabilities Education Improvement Act, intellectual disabilities, discipline, 504, and special education programs in general. Her research interests include secondary campus leadership and knowledge of and training in special education policy and procedures.

Liz Shelby has a doctoral degree in special education administration at the University of Texas at Austin. She has over 40 years of experience coordinating programs and services for people with disabilities, including early childhood intervention, a statewide family support program, and permanency planning for children with disabilities living in institutions. Her research interests include family supports and alternatives to institutional placement for children with intellectual disabilities. She volunteers on an advisory committee for the local center for mental health 
and developmental disabilities services and is board vice president of a nonprofit serving adults and their families experiencing mental health issues.

Barbara L. Pazey is an assistant professor in the departments of special education and educational administration at the University of Texas at Austin. She holds a doctorate in educational administration/special education administration from the University of Texas at Austin. Her research focuses on the development of socially just leadership and teacher education preparation programs that honor and empower student voice and the academic, social, and emotional needs of special population students at the secondary level.

James R. Yates is the John L. and Elizabeth G. Hill Centennial Professor in Education at the University of Texas at Austin, where he holds appointments in the Department of Educational Administration and the Department of Special Education. $\mathrm{He}$ is the director of the doctorate program in special education administration, which integrates general and special education leadership preparation. His research reflects an interest in educational organization response to the needs of students and families with special needs, students with disabilities, Englishlanguage learners, lower socioeconomic students, incarcerated youth, and minority students. 